\title{
An Epidemiologic Study of Patients Presenting with Burns and Scald Injuries to a Government Medical College Hospital in Karnataka
}

\author{
Ramakrishna Siddaya ${ }^{1}$, Subhas Babu Puttamaligaiah ${ }^{2 *}$, Harish Bekkalale Rudresh ${ }^{2}$, Nagaraja Goud \\ Bhoompuram², Vinay Muninarayanaswamy²
}

\section{Ramakrishna Siddaya', Subhas Babu Puttamaligaiah ${ }^{2 *}$, Harish Bekkalale Rudresh², Nagaraja Goud Bhoompuram², Vinay Muninarayanaswamy ${ }^{2}$}

'Department of General Medicine, Mandya Institute of Medical Sciences, Mandya, Karnataka, INDIA. ${ }^{2}$ Department of Community Medicine, Mandya Institute of Medical Sciences, Mandya, Karnataka, INDIA.

Correspondence

Dr. P. Subhas Babu

Department of Community Medicine, Mandya Institute of Medical Sciences, Bangalore-Mysore Road, Mandya,

Karnataka-571401, INDIA.

Phone no: +919481889628

Email: p.subhash.babu@gmail.com

History

- Submission Date: 19-01-2020

- Revised Date: 06-03-2020

- Accepted Date: 10-05-2020

DOI : 10.5530/ijmedph.2020.2.12

Article Available online

http://www.ijmedph.org/v10/i2

Copyright

(C) 2020 Phcog.Net. This is an openaccess article distributed under the terms of the Creative Commons Attribution 4.0 International license.

\section{ABSTRACT}

As per the World Health Organization's Global burden of disease (GBD) estimates in 2004 about 3,10,000 people (30\% of them under 20 yrs of age) died due to burn injuries and 237500 in 2013 as per GBD 2013. In terms of years of life lost, deaths/ injuries due to fire ranked $25^{\text {th }}$ in 1990 and $34^{\text {th }}$ in 2013. In India, as per data released by National Crime Record Bureau in the year 2013, electrocution and fire accidents were responsible for $2.6 \%$ and $5.5 \%$ of the total deaths due to accidents respectively. Injury due to burns leads to significant mortality and morbidity, so this study was done with the following objectives. To determine the profile of the victims of burns and scald injuries treated at the MIMS hospital. To quantify the morbidity, mortality due to burns and scalds in patients treated in MIMS hospital. To determine the reasons for burns/ scald injuries among the victims. Methodology: A Cross sectional, hospital based study was done sourcing data from medical records of admitted patients from January 2013 to December 2013. Results and Discussion: The total number of patients admitted with burn injuries during the study period were 217 of which 189 sustained burns/ scald injuries and the remaining sustained electrical burn injuries. 122 were aged between 16-35 yrs. Of the 189 people who sustained burns/ scald injuries 33 were children aged 15 yrs or less. The risk of females sustaining critical burn injuries ( $>25 \%$ body surface area) was statistically significant in adults.

Key words: Burns and Scalds, Injuries, Epidemiology, Government Medical College, Karnataka.

\section{INTRODUCTION}

Injuries are an important cause for morbidity and mortality to which burns and scalds also contribute significantly. According to the WHO global burden of disease estimates for 2004, about 3,10,000 people died as a result of fire-related burns, of which $30 \%$ were under the age of 20 years $^{1}$ and 237500 died in 2013 as per GBD 2013. ${ }^{2}$

Electrocution and fire accidents were responsible for $2.6 \%(10,218)$ and $5.5 \%(22,177)$ of the total deaths, respectively due to accidents. ${ }^{3}$ In Brazil and India, infants account for nearly half of all childhood burns ${ }^{4}$ Burn injuries are the second largest group of injuries after road accidents. $10 \%$ of these are life threatening and require hospitalization. Around $70 \%$ of burns occur in the most productive age group (15-40yrs) ${ }^{5}$ About $80 \%$ of all admitted cases occur due to accidents in kitchen.

As per the National Crime Records Bureau, Ministry of Home affairs report on Accidental Deaths and Suicides in India 2013, females outnumbered males in deaths due to fire accidents $(65.7 \%$ compared to

$34.3 \%)$. Also among the $1,34,799$ suicides reported, a significant number of persons (7.4\%) committed suicide by fire/ self immolation ${ }^{3}$

Burns and scalds are injuries sustained in various settings and due to different reasons ranging from occupational to domestic.

\section{Need for the study}

Injuries sustained due to burns and scalds are mostly unintentional, but some may also be intentional (suicidal/ homicidal). Many of the burns and scald injuries leave residual disability and scarring which add to the future health care costs. Majority of the injuries are preventable.

The specific reasons and conditions under which burns and scald injuries sustained by victims of different age and sex group are usually different. The reasons if explored particularly at the district level, will help to understand the circumstances of burn injuries and 
help recommend local interventions and help reduce the burden of morbidity and mortality due to burns and scalds.

\section{Objectives}

- To determine the profile of the victims of burns and scald injuries treated at the MIMS hospital

- To quantify the morbidity, mortality due to burns and scalds in patients treated in MIMS hospital

- To determine the reasons for burns/ scald injuries among the victims

\section{MATERIALS AND METHODS}

Type of study: Cross sectional, Descriptive study, done for one year from January 2013 to December 2013.

Tool for data collection: In patient records and Medico Legal Case Register.

\section{Inclusion criteria}

All patients admitted to the Medical College Hospital with history of injuries due to burns (including electrical injury) and scalds.

\section{Exclusion criteria}

Incomplete records in either of the in-patient records or MLC registers for retrospective cases.

Patients brought dead to the casualty were not included.

Permission was sought from the Institutional Ethics Committee for prospective data collection in the year 2014 but permission was given for retrospective data collection. Data regarding all burn injuries in the year 2013 was collected.

Data collection - Data regarding burns patients was collected from Accident register/ Medico-legal case register at the Casualty and from in patient records of admitted burns patients. The information from the register and case sheet was entered separately into a structured format for ease of data entry.

Data entry and analysis - Data collected in the structured format was entered into Microsoft Excel ${ }^{\mathrm{TM}}$ spreadsheet document and analyzed using the same.

\section{RESULTS AND DISCUSSION}

A total of 217 members were admitted to Mandya Institute of Medical Sciences, during the year 2013 from January to December with history of burns or scalds. Of them 118 (54.38\%) were males and 99 (45.62\%) were females. Children aged less than or equal to 15 years accounted for 36 (16.59\%) patients.

Most of the injured victims who sustained burns/ scalds and electrical injuries were aged between 16 yrs to 35 yrs with a male preponderance across all age groups.

Age of the victims of injuries due to fire/ scalds or electric burns ranged from 8 months - 75 yrs for males and for females 7 months - 73 yrs.

As per a hospital based study done in Belgaum district in Karnataka, the mean age of burn injury was 29.32 years ranging from 4 months to 95 years and $52.63 \%$ of the patients being females. ${ }^{6}$ Table 1

Number of patients who had electrical burns/ electrocution were 28 (Males $=23$, Females $=5)$ of which $\leq 15$ yrs were $3(2$ males and 1 female)

Most of the electrical burns occurred in homes of victims (16/28), 6 were due to handling cable, or at Workplace $(4 / 28)$
Patients who suffered scald injury were 42 (Females $=23$; aged 7 months to $60 \mathrm{yrs}$ and Males $=19$; aged $1 \mathrm{yr}$ to $56 \mathrm{yrs}$ ) Most of the scald injuries occurred at home and were associated with cooking, spillage while serving of hot food (sambar etc.), or while taking bath (accidental use of very hot water) the circumstances in which these injuries were sustained match the risk factors mentioned in WHO plan for burns prevention and care. As also mentioned in the report these risk factors are amenable to prevention efforts. ${ }^{7}$

Patients with burns or scald injuries were $n=189$ of which 147 were Burns injuries (16 - ritual/ intentional). Table 2

For estimating the body surface area of involvement in burns, electric burns were excluded. Rule of nine was used to estimate the body surface area involved in case of adults, Lund and Browder chart was used for children (less than or equal to $15 \mathrm{yrs}^{8}$ Depth of injury was not assessed as it was not uniformly mentioned in the records (not mentioned at all in some records).

As per practical handbook used under the National Programme for Prevention, Management and Rehabilitation of Burn Injuries (NPPMRBI) in India the severity of burns in terms of Total body surface area (TBSA) involved was classified as minor for $<10 \%$ in children and $<15 \%$ in adults, moderate $10-15 \%$ TBSA in children and $15-25 \%$ TBSA in adults, critical $>15 \%$ TBSA in children and $>25 \%$ TBSA in Adults ${ }^{5}$

The cut off age to grade the severity of burns between children and adults was taken as 15 yrs, this being the higher range of age as per Lund and Browder modification of rule of nine to assess area of burns. ${ }^{8}$

Children $\leq 15$ yrs excluding electrical burns $=33(\mathrm{M}=18, \mathrm{~F}=15)$

Aged $>15$ yrs excluding electrical burns $=156(\mathrm{M}=77, \mathrm{~F}=79)$

Though there was no statistically significant difference in the risk of burn injuries between male and female children, the risk of females sustaining critical burn injuries was statistically significant in adults. Table 3

The reasons were broadly categorised into intentional or unintentional. Among males $56.6 \%$ ( $n=76$ ) of the burn injuries were allegedly accidental/ unintentional. Among males mention needs to be made of another category of 'intentional' injury where burns were sustained while performing a ritual of jumping along with cattle over a pyre during the festival of makara sankranti, which accounted for $21.05 \%(n=76)$ of the

\begin{tabular}{|c|c|c|c|}
\hline & Male & Female & Total \\
\hline$<15$ yrs & 20 & 16 & 36 \\
\hline $16-35 y r s$ & 65 & 57 & 122 \\
\hline $36-55$ yrs & 25 & 20 & 45 \\
\hline$>55 \mathrm{yrs}$ & 8 & 6 & 14 \\
\hline Total & 118 & 99 & 217 \\
\hline
\end{tabular}

$\mathrm{N}=217$ Males -118 Females -99

\begin{tabular}{|c|c|c|c|}
\hline & Male & Female & Total \\
\hline Burns & $76(64.41 \%)$ & $71(71.72 \%)$ & $147(67.74 \%)$ \\
\hline Scalds & 19(16.10\%) & $23(23.23)$ & $42((19.35 \%)$ \\
\hline Electrical -burns & $23(19.49 \%)$ & $5(5.05 \%)$ & $28(12.90 \%)$ \\
\hline Total & 118 & 99 & 217 \\
\hline
\end{tabular}

Chi square value $=10.54$, d. $f=3$, $p$ value $=0.0051$ 


\begin{tabular}{|c|c|c|c|c|}
\hline & $\begin{array}{c}\text { Minor } \\
<10 \% \\
\text { and }<15 \%\end{array}$ & $\begin{array}{l}\text { Moderate } \\
\text { 10-15\% (in } \\
\text { children) } \\
\text { and } 15-25 \% \\
\text { (adults) }\end{array}$ & $\begin{array}{l}\text { Critical } \\
>15 \% \\
\text { (children) } \\
>25 \% \\
\text { (adults) }\end{array}$ & Total \\
\hline $\begin{array}{l}\text { Children } \\
\text { ( }<15 \text { yrs) }\end{array}$ & $17(F=6, M=11)$ & $8(F=6, M=2)$ & $8(F=3, M=5)$ & 33 \\
\hline Male & 11 & 2 & 5 & 18 \\
\hline Female & 6 & 6 & 3 & 15 \\
\hline Adult & $\begin{array}{c}63(F=24, \\
M=39)\end{array}$ & $\begin{array}{c}29(F=11, \\
M=18)\end{array}$ & $\begin{array}{c}64(F=44, \\
M=20)\end{array}$ & 156 \\
\hline Male & 39 & 18 & 20 & 77 \\
\hline Female & 24 & 11 & 44 & 79 \\
\hline
\end{tabular}

Children, Chi square $=3.72$, d. $\mathrm{f}=2, P$ value $=0.155$

Adults, Chi square $=14.24$, d. $\mathrm{f}=2, P$ value $=0.00080$

\begin{tabular}{|c|c|c|c|}
\hline & Burns & Scalds & Grand Total \\
\hline Male & 76 & 19 & 95 \\
\hline Accidental/ Unintentional & 43 & 19 & 62 \\
\hline Intentional & 17 & 0 & 17 \\
\hline Ritual/ Intentional & 16 & 0 & 16 \\
\hline Female & 71 & 23 & 94 \\
\hline Accidental/ Unintentional & 57 & 23 & 80 \\
\hline Intentional & 14 & 0 & 14 \\
\hline Grand Total & 147 & 42 & 189 \\
\hline
\end{tabular}

burn injury cases. This is one cause for burn injury, amenable to prevention where adequate IEC activities can be taken up during the season to educate people regarding precautionary and preventive measures to be taken to avert burn injuries. Among females who sustained burn injuries, $78.87 \%(n=71)$ were accidental burns as per records (also categorised as unintentional) with most of them occurring at home. Table 4

\section{Outcomes}

1. Death - 5 (All females) of which 2 were intentional (suicidal), 3 accidental (Area of burns involved ranged from 29\% to 93.5\%) All fire injuries leading to death happened at home. Female patients outnumbered males. Burn injuries among females are mostly fatal when compared to males. As per a study done in Latur, Maharashtra $73.72 \%$ females patients died because of the burn whereas males were only $26.28 \%{ }^{9}$

As per a study done in Chandigarh, among the victims who succumbed to burn injuries the total body surface area involved was more than $80 \%$ in about $8 \%$ of victims to less than $30 \%$ body surface area in about $6 \%$ of the victims. Majority of the victims who succumbed to burn injuries had suffered burn injuries between $51-60 \%(27 \% n=372)^{10}$

2. Referred directly to higher centre or admitted and then referred -7

3. Admitted/ admitted and discharged - 123/217 OPD basis $-82 / 217$

\section{Management and outcome of burn injury victims for upto one week period from admission}

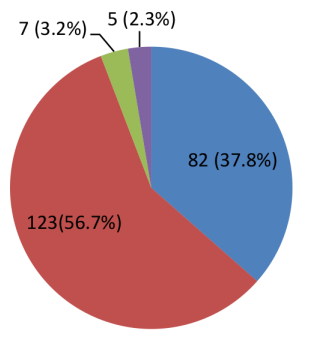

- OPD basis

- Admission and discharge

neferred

- Death

\section{CONCLUSION}

A considerable number of people sustain burns and scald injuries and seek care at tertiary level for wound management and rehabilitation. Males and Females are equally vulnerable for burns and scald injuries with extremes of age being more at risk. Women and children being are especially at risk for scald injuries. Men are more likely to sustain electrical burn injury than women. Adult females have a higher likelihood of sustaining serious burn injuries involving $>25 \%$ of body surface areas in terms of wounds sustained when compared to adult males. Most of the burn injuries sustained by the victims are unintentional, but nevertheless could have been prevented if precautionary measures were taken.

\section{ACKNOWLEDGEMENT}

The Medical Superintendent, MIMS Hospital for permitting for data collection from the hospital records. The Staff, Medical Records Department of MIMS Hospital, for cooperating in retrieval of records and data collection from case sheets.

\section{CONFLICT OF INTEREST}

None

\section{ABBREVIATIONS}

MIMS: Mandya Institute of Medical Sciences; WHO: World Health Organization; GBD: Global Burden of Disease; MLC: Medico Legal Case; TBSA: Total Body Surface Area; OPD: Out Patient Department; NPPMRBI: National Programme for Prevention, Management and Rehabilitation of Burn Injuries.

\section{REFERENCES}

1. Global Burden of Disease Update. World Health Organization. 2004. Available from (https://www.who.in/healthinfo/global_burden_disease/2004_report_update/en/)

2. Global, regional and national age-sex specific all-cause and cause-specific mortality for 240 causes of death, 1990-2013: a systematic analysis for the Global Burden of Disease Study 2013 GBD 2013 Mortality and Causes of Death Collaborators. 2015;385:138. www.thelancet.com (available from URL https:// www.thelancet.com/pdfs/journals/lancet/PIIS0140-6736(14)61682-2.pdf

3. National Crime Records Bureau, Ministry of Home Affairs, Government of India. Crimes in India and Accidental Deaths and Suicides in India. 2013. (Available from URL http://ncrb.gov.in)

4. World Report on Child Injury prevention. available from URL https://www.who. int/violence_injury_prevention/child/injury/world_report/en/

5. Practical Handbook of Burns Management, For National Programme for Prevention, Management and Rehabilitation of Burn Injuries (NPPMRBI) Under Ministry of Health and Family Welfare Government of India available from URL https://dghs.gov.in/WriteReadData/userfiles/file/Practical_handbook-revised_ Karoon.pdf 
6. Shankar G, Naik V A, Powar R, Honnungar R, Mallapur M D. Epidemiology and Outcome of Burn Injuries J Indian Acad Forensic Med. 2012;34(4):312-4. http:// medind.nic.in/jal/t12/i4/jalt12i4p312.pdf

7. A WHO Plan for burn prevention and care. World Health Organization, Geneva Switzerland. 2008. available from URL https://apps.who.int/iris/handle/10665/ 97852

8. Lee KC, Joory K, Moiemen NS. History of burns: The $\mathrm{p}^{*}$ ast, present and the future. Burn Trauma. 2014; 2:169-80. doi:10.4103/2321-3868.143620

9. Patil SW, Parmar DR. Mortality Associ-ated with Burn Injuries: An Observational Cross Sectional Study from Latur, Maharashtra. Ntl J Community Med. 2016;7(2):121-4. http://njcmindia.org/uploads/7-2_121-124.pdf

10. Sharma BR, Harish D, Sharma A, Sharma S, Singh H. Accidental burns in Indian kitchens: Are they really accidental?. JIAFM. 2006;28(1):14-7. available from URL http://medind.nic.in/jal/t06/i1/jalt06i1p14.pdf

Cite this article : Ramakrishna S, Babu SP, Harish BR, Goud BN, Vinay M. An Epidemiologic Study of Patients Presenting with Burns and Scald injuries to a Government Medical College Hospital in Karnataka. Int J Med Public Health. 2020;10(2):54-7. 